\title{
Should lymphangioleiomyomatosis patients be permitted to donate blood?
}

\begin{abstract}
To the Editor:
Lymphangioleiomyomatosis (LAM) is a rare disease, seen primarily in women and characterised by cystic lung destruction, renal angiomyolipoma and lymphatic abnormalities (e.g. lymphangioleiomyomas) [1]. LAM occurs sporadically in 3-7.8 women per million, and in tuberous sclerosis complex (TSC), an autosomal dominant disorder, that occurs in 1:5800 live births [1]. LAM behaves as a slowly progressive, chronic neoplasm $[2,3]$, which results from proliferation of phenotypically and genetically heterogeneous LAM cells [1]. Similar to cancer cells, LAM cells are capable of metastasis, invasion and destruction of surrounding matrix [3]. Circulating LAM cells, detected in $\sim 90 \%$ of patients, can be isolated from blood, urine and chyle, and presumably, represent a mechanism for metastasis [4]. The disease responds to treatment with sirolimus (rapamycin), an inhibitor of mechanistic target of rapamycin, which was recently approved by the US Food and Drug Administration (FDA) for LAM. Sirolimus stabilises lung function, shrinks angiomyolipomas and lymphangioleiomyomas, and reduces the ability to detect circulating LAM cells $[1,5]$. LAM-related tumours, however, can still be identified by imaging studies.
\end{abstract}

The question has been raised as to whether LAM patients can donate blood for transfusion to others. There is no specific directive against donation by LAM patients or published reports of LAM "transmission" by transfusion. Blood-collecting agencies would evaluate the issue within the current regulatory framework in their jurisdiction for allogeneic blood donation. These policies generally share common principles to protect donor safety. All US blood centres must comply with FDA regulations that govern the eligibility of volunteer blood donors. The blood centre's physician must determine that the prospective donor is in good health, will not be adversely affected by blood donation and is free of conditions that could adversely affect the "safety, purity or potency" of the blood and blood components [6]. Likewise, the Council of Europe has established comparable standards and recommendations for their 47 member states to assure donor health [7]. In addition, AABB (formerly, the American Association of Blood Banks) promulgates voluntary accreditation standards that are used internationally to promote the safety and quality of blood collection. AABB requires accredited blood centres to determine that the prospective donor is in good health and free of major organ disease or cancer, unless the medical director otherwise determines they are suitable to donate blood or blood components [8]. Most blood centres use a standard screening tool, the Donor History Questionnaire, to elicit information from donors about their health. In addition, prospective blood donors must have acceptable haemoglobin and physical findings. Regulations and standards permit some flexibility and allow for medical evaluation where no evidence exists regarding the possible effect of blood donation on the donor's health or risk to transfusion recipients.

Consequently, the additional criteria that blood centres use to evaluate prospective donors with a history of cancer, or in this case, a LAM diagnosis, are left to medical discretion and can differ among blood centres. Given the similarities between LAM and cancer, the same reasoning could be applied to consider whether the condition poses risk to the transfusion recipient and whether the subject's state of health permits blood donation. To date, there have been no documented cases of cancer transmission through blood transfusion. In addition, evidence supports the conclusion that the risk of transmitting cancer through transfusion is negligible [9]. Still, individuals with evidence of cancer or who are currently being treated for cancer would not be accepted as blood donors as a precaution and to protect their health. Individuals with localised skin cancers and carcinoma in situ are eligible after curative treatment and recovery. Most blood centres will also accept individuals who have completed treatment for non-haematological cancer after variable periods of time without relapse, usually 1-5 years. Blood centres typically defer individuals with haematological malignancies permanently from blood donations. By analogy to cancer, the persistence of LAM tumours and cells and concern for the donor's underlying health would lead many to conclude that these individuals should be permanently deferred from allogeneic blood donation. http://ow.ly/10CM0k 
Anne F. Eder ${ }^{1}$, Jay H. Ryu ${ }^{2}$ and Joel Moss ${ }^{3}$

${ }^{1}$ Blood Services Section, National Institutes of Health, Clinical Center, Department Transfusion Medicine (CC/DTM), Bethesda, MD, USA. ${ }^{2}$ Division of Pulmonary and Critical Care Medicine, Mayo Clinic College of Medicine, Mayo Clinic, Rochester, MN, USA. ${ }^{3}$ Cardiovascular and Pulmonary Branch, National Institutes of Health, National Heart, Lung, and Blood Institute, Bethesda, MD, USA.

Correspondence: Joel Moss, National Institutes of Health, Building 10, Room 6D05, MSC 1590, Bethesda, MD $20892-$ 1590, USA. E-mail: mossj@nhlbi.nih.gov

Received: Feb 252016 | Accepted after revision: March 162016 | First published online: April 212016

Conflict of interest: None declared.

Support statement: J. Moss was funded by the Intramural Research Program, National Institutes of Health, National Heart, Lung, and Blood Institute.

\section{References}

1 Harari S, Torre O, Cassandro R, et al. The changing face of a rare disease: lymphangioleiomyomatosis. Eur Respir J 2015; 46: 1471-1485.

2 Henske EP, McCormack FX. Lymphangioleiomyomatosis - A wolf in sheep's clothing. J Clin Invest 2012; 122: 3807-3816.

3 McCormack FX, Travis WD, Colby TV, et al. Lymphangioleiomyomatosis: calling it what it is: a low-grade, destructive, metastasizing neoplasm. Am J Respir Crit Care Med 2012; 186: 1210-1212.

4 Cai X, Pacheco-Rodriguez G, Fan QY, et al. Phenotypic characterization of disseminated cells with TSC2 loss of heterozygosity in patients with lymphangioleiomyomatosis. Am J Respir Crit Care Med 2010; 182: 1410-1418.

5 Cai X, Pacheco-Rodriguez G, Haughey M, et al. Sirolimus decreases circulating lymphangioleiomyomatosis cells in patients with lymphangioleiomyomatosis. Chest 2014; 145: 108-112.

6 Food and Drug Administration, Department of Health and Human Services. Requirements for blood and blood components Intended for Transfusion or for further manufacturing use; Final Rule. Silver Spring, FDA, 2015.

7 European Directorate for the Quality of Medicines and HealthCare. Guide to the preparation, use and quality assurance of blood components. Recommendation No. R(95)15, 18th edition; Council of Europe, 2015. www.avis.it/ userfiles/file/News/EDQM\%20Guide\%2018th\%20edition.pdf. Date last accessed: February 23, 2016. Date last updated: July 6, 2015.

8 AABB. Standards for Blood Banks and Transfusion Services. 29th Edn. Bethesda, AABB, 2015.

9 Eder AF. Blood Donors with a History of Cancer. In: Eder A, Bianco C, eds. Screening Blood Donors: Science, Reason, and the Donor History Questionnaire. Bethesda, AABB Press, 2007.

Eur Respir J 2016; 47: 1883-1884 | DOI: 10.1183/13993003.00410-2016 The content of this work is not subject to copyright. Design and branding are CERS 2016. 